\title{
A Study on Cloud-based Safety ESS Watchdog System Using Ultra-Compact Wireless Sensor
}

\author{
Song-Do Ki ${ }^{1,2}$, Seok-hwan Cho ${ }^{1,2}$, Hwan-su Lee ${ }^{1}$, Dae-Kyong Kim ${ }^{2,3 *}$ \\ ${ }^{1}$ Enitt, Naju-si, Jeollanam-do, Republic of Korea \\ 2 Sunchon National University, Korea \\ * 3 Smart Energy Institute, Sunchon National University, Korea \\ *dkkim@sunchon.ac.kr
}

\begin{abstract}
Article History:Received:11 november 2020; Accepted: 27 December 2020; Published online: 05 April 2021
Abstract: Background/Objectives: Safety matters are being discussed and countermeasures to prevent various breakdowns/accidents are urgently required. Therefore, we propose a safety management solution for ESS fire monitoring. Methods/Statistical analysis: BLE 5.0-based ultra-compact wireless sensor-based edge that can detect off-gas early, as well as measure the temperature, humidity, vibration, and smoke in the golden time of approximately 10 minutes from the occurrence of thermal runaway inside the ESS to a fire. This paper proposes a safety system and an ESS-integrated safety management solution. Findings: It is known that the ESS currently in operation is installed without an integrated control method and a systematic protection system between facilities in order to connect new and renewable energy and to quickly supply the site, so there are many problems. For this reason, various accidents such as reactor failure and fire are occurring in the ESS installed at the actual site. Recently, 22 fires occurred in ESS facilities installed nationwide in 2019, and the government has urgently stopped ESS operation and formed a joint public-private investigation committee to clarify the cause. Among the various causes of ESS fires that have been raised, the ESS design should be considered. This paper reported an edge safety-based on BLE 5.0 that is capable of detecting off-gas and detecting temperature, humidity, vibration, and smoke early in the golden time of approximately 10 minutes from the occurrence of thermal runaway inside the ESS to a fire. A system and ESS integrated safety management solution were proposed. In this study, internal monitoring of an ESS was possible by integrating directly with existing and new ESS. The administrator can observe all conditions on the web through the cloud-based ESS integrated safety management system. Improvements/Applications: This paper analyzed and developed a cloud-based ESS integrated safety management system. It will be helpful in ESS fire management in the future and will be useful in designing artificial intelligence-based safety management solutions.
\end{abstract}

Keywords: ESS, Fire prevention, Wireless sensor, edge computing, gas sensor.

\section{Introduction}

As environmental problems, such as fine dust and global warming, have arisen, and the demand for clean energy has increased. With this, the use of wind and solar power has increased. An increasing number of new and renewable distributed power sources are being installed. Accordingly, the government expanded the use of new and renewable energy sources by introducing 'renewable energy 3020', and ESSs (Energy Storage Systems) to increase the reliability of the system because of the increase in distributed generation sources without system inertia. Applications are also increasing [1-3]. On the other hand, the currently operating ESSs have a range of problems because they are installed without an integrated control method or a systematic protection system between the facilities for new and renewable linkages and rapid on-site supply. Therefore, many accidents, such as reactor failure and fire, have occurred in ESSs installed at actual sites [4-7]. Recently, 22 fires occurred in 2019 in ESS facilities installed nationwide. As a result, the Korean Government urgently stopped the use of ESSs and formed a joint public-private investigation committee to determine the causes of these accidents. Various causes of ESS fires need to be considered when designing ESS safety procedures, and measures to prevent failures/accidents are needed urgently [8-10]. Currently, the development of technology related to preventing fires in ESSs in Korea is mainly in the development stage, with most studies performed by large companies, such as Samsung SDI, LG Chemical, and Hyosung Heavy Industries. The research in this area has focused mainly on preventing battery cell defects in the production process, monitoring PCS, arc occurrence, cell separator, and surge insulation destruction. Technology development is underway. Therefore, this paper reports a BLE 5.0-based ultra-compact wireless sensor-based edge that can detect off-gas early, as well as measure the temperature, humidity, vibration, and smoke in the golden time of approximately 10 minutes from the occurrence of thermal runaway inside the ESS to a fire. This paper proposes a safety system and an ESS-integrated safety management solution[11,12].

\section{Main subject}

\subsection{Artificial Intelligence-based Safety ESS Watchdog System}

Figure 1(a) presents the conceptual diagram of the Safety ESS Watchdog System. The BLE 5.0-based

*Corresponding author: Dae-Kyong Kim²

Smart Energy Institute, Sunchon National University, Korea

dkkim@sunchon.ac.kr 
gateway for data collection was applied to this system, and multiple communication interfaces were implemented to support interworking with various facilities and external platforms. In addition, the PKI algorithm security chipset board for edge-device security authentication and server-interworking communication security function implementation, as well as a high-speed edge rules engine service for realtime ESS operation status monitoring and control, were applied. Figure 1(b) shows the Edge Rules data model. The Edge Rules Engine Service has an automatic operation scheduler function, event alarm logging/management function, real-time data visualization, emergency stop function, and real-time stream data analysis function. In addition, to analyze the correlation of the sensor data, a deep learning-based ESS fire prediction and detection algorithm was applied to analyze the correlation of five sensor data and real-time RNN Recurrent Neural Network. The LSTM algorithm was also applied to perform model training and correct the learning errors of the RNN technique, as shown in Figure 1(c).

(a)

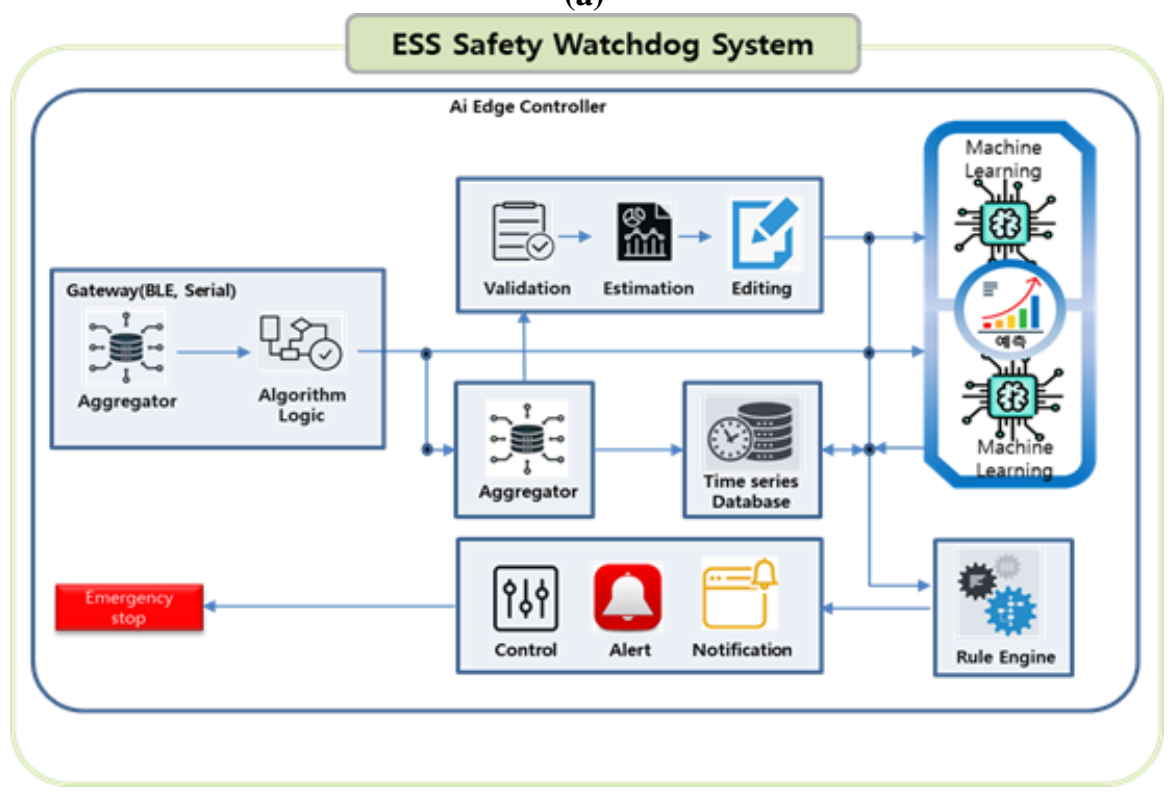

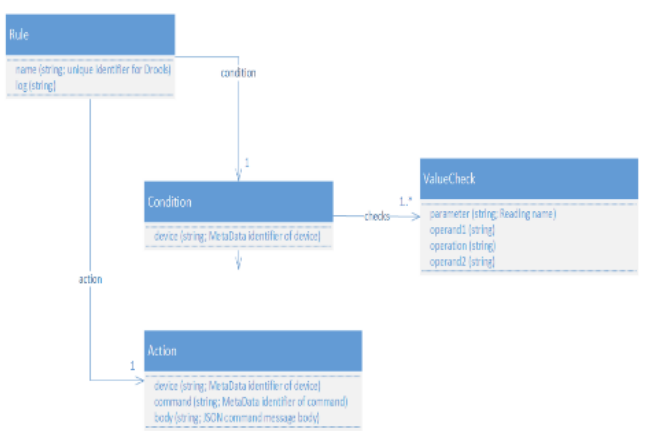

(b)

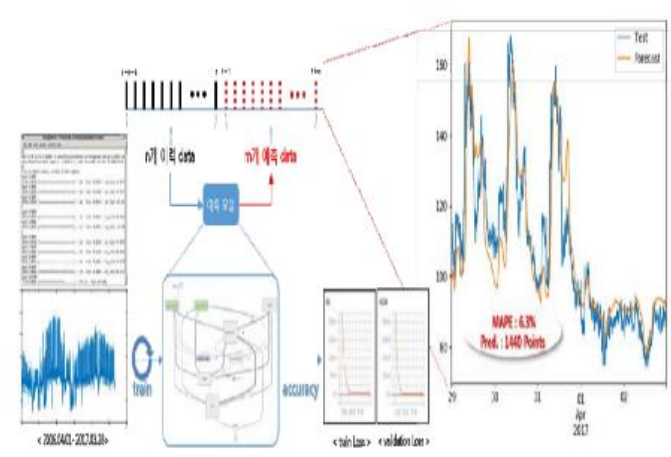

(c)

Figure 1. (a) Concept diagram of Safety ESS Watchdog System (b)Edge Rules data model (c) Machine data based fire prediction model for machine learning

\subsection{Cloud-based ESS integrated safety management system}

In the ESS integrated safety management system, various ESS-type setting functions and data maps were implemented for the integrated management of ESSs, and a device-object structure and ESS-type support communication interface were used for integrated management of multiple ESSs at a distance. Figure 2(a) presents the Cloud-based ESS integrated safety management system conceptual diagram. Therefore, ESSintegrated management is possible in real-time, and ESS integrated monitoring, individual monitoring, and emergency control functions are provided. If an emergency event occurs, an alarm is announced on the user's web; Figure 2(b) presents the Safety ESS integrated safety management system data flow chart. 


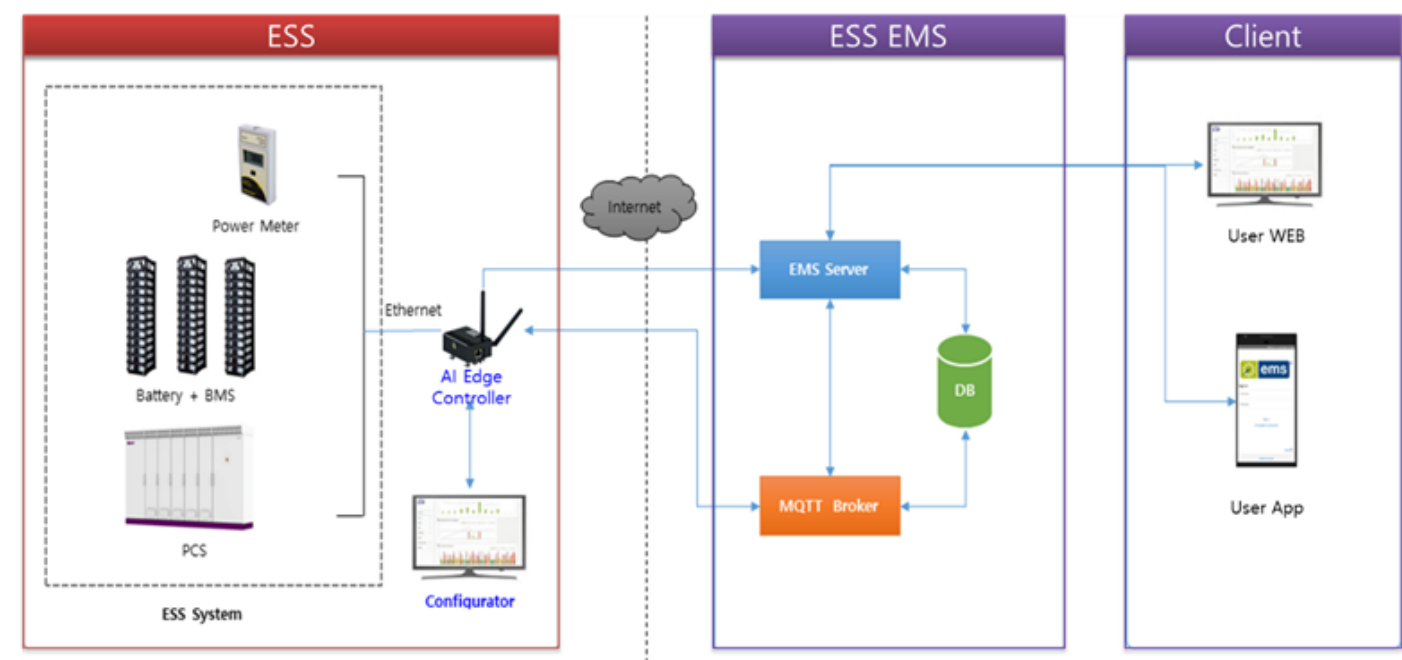

(a)

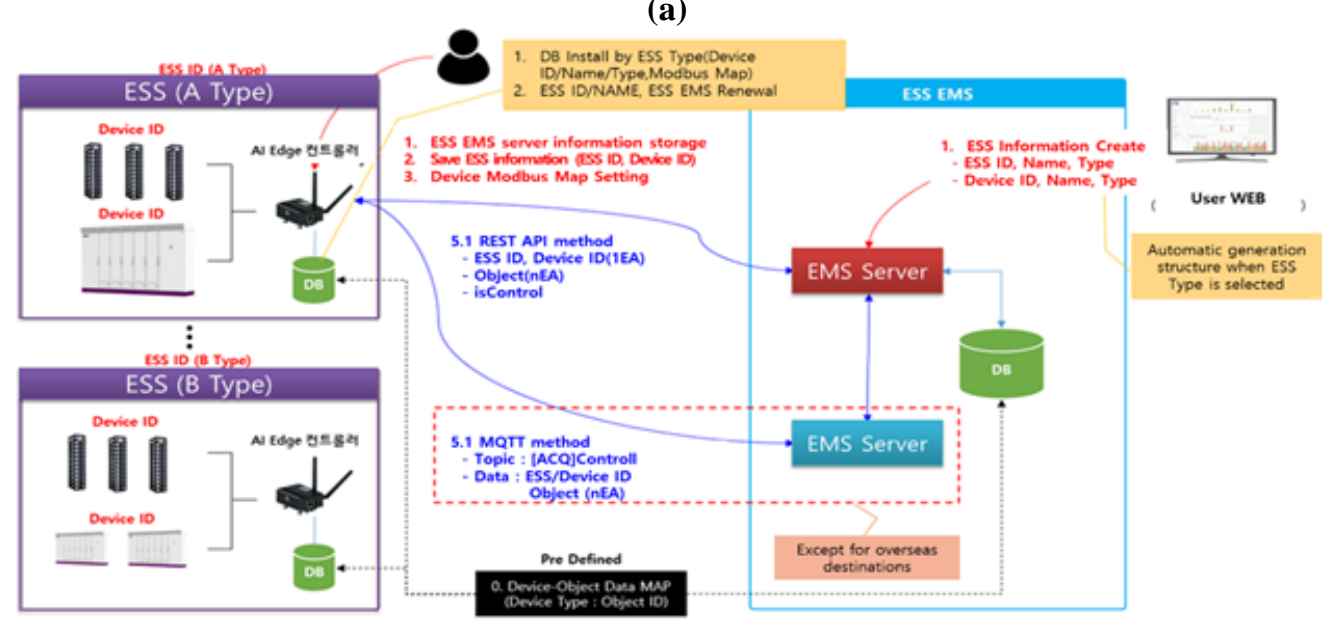

(B)

Figure 2. (a)Cloud-based ESS integrated safety management system conceptual diagram (b)Safety ESS integrated safety management system data flow chart

\subsection{BLE 5.0 based compact wireless sensor module}

To pre-detect fire-causing factors, five types of sensors were applied: temperature, humidity, smoke, vibration, and off-gas sensors. This ultra-compact wireless sensor was equipped with an attached sensor case using neodymium magnets and non-combustible materials so it can be installed easily in a battery rack (RACK) and perform communication and sensing functions for a certain period (five minutes or more) during a fire. In addition, a low-power wireless communication method was applied to secure a long battery replacement cycle. Figure 3(a) shows the shape of the five sensors. Figure 3(b) and Table 1 show the sensor installation method, type, location, and number according to the monitoring equipment. In addition, fire-level diagnosis and fire prevention/response according to the action plan were prepared, as shown in Table 2. Figure 4 Example of offgas sensor product shape and ESS RACK installation method. Figure 5 shows the BLE sensor mechanism, composition and parts arrangement.

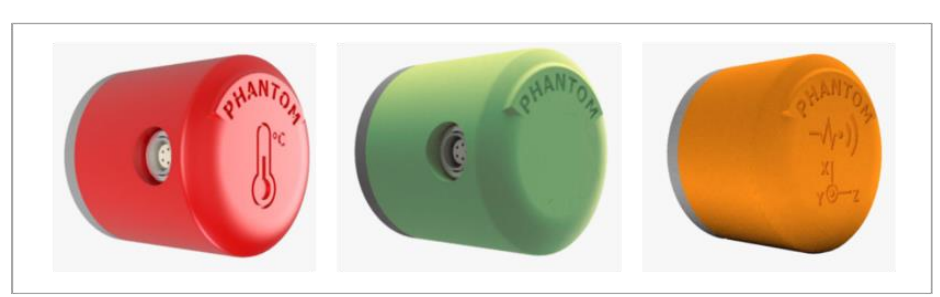

(a)

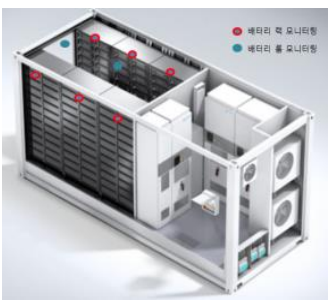

(b)

Figure 3. (a) Prototype of ultra-small wireless sensor module (b) Sensor installation location according to monitoring equipment 

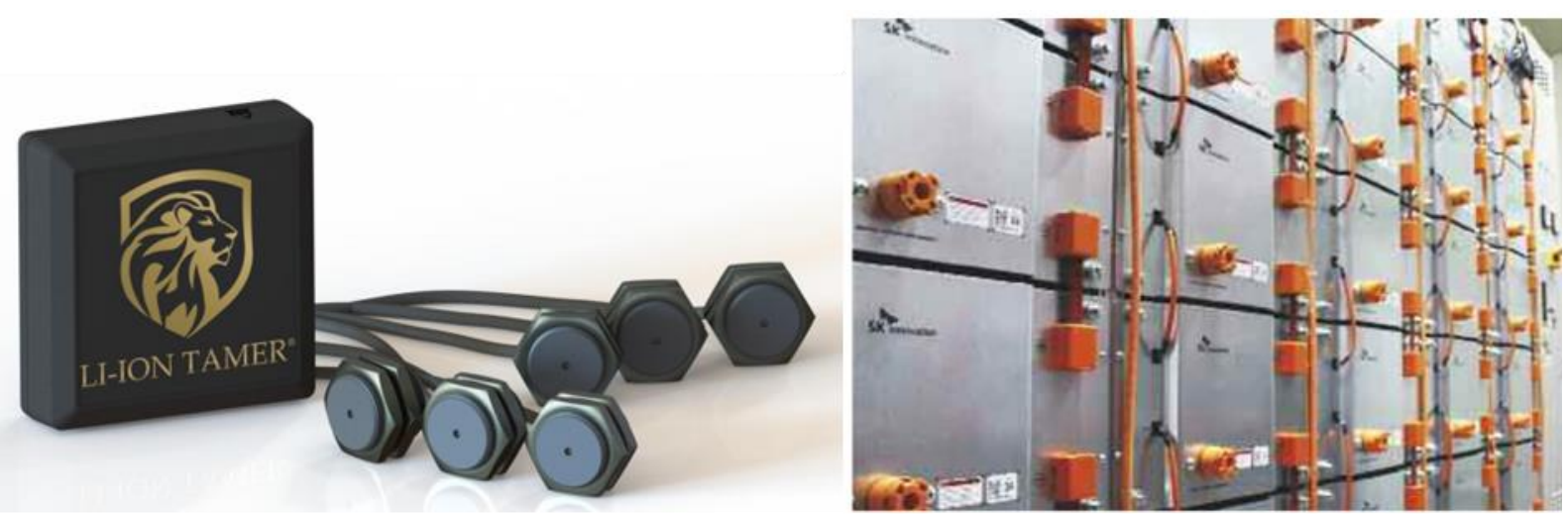

Figure 4. Example of off-gas sensor product shape and ESS RACK installation method
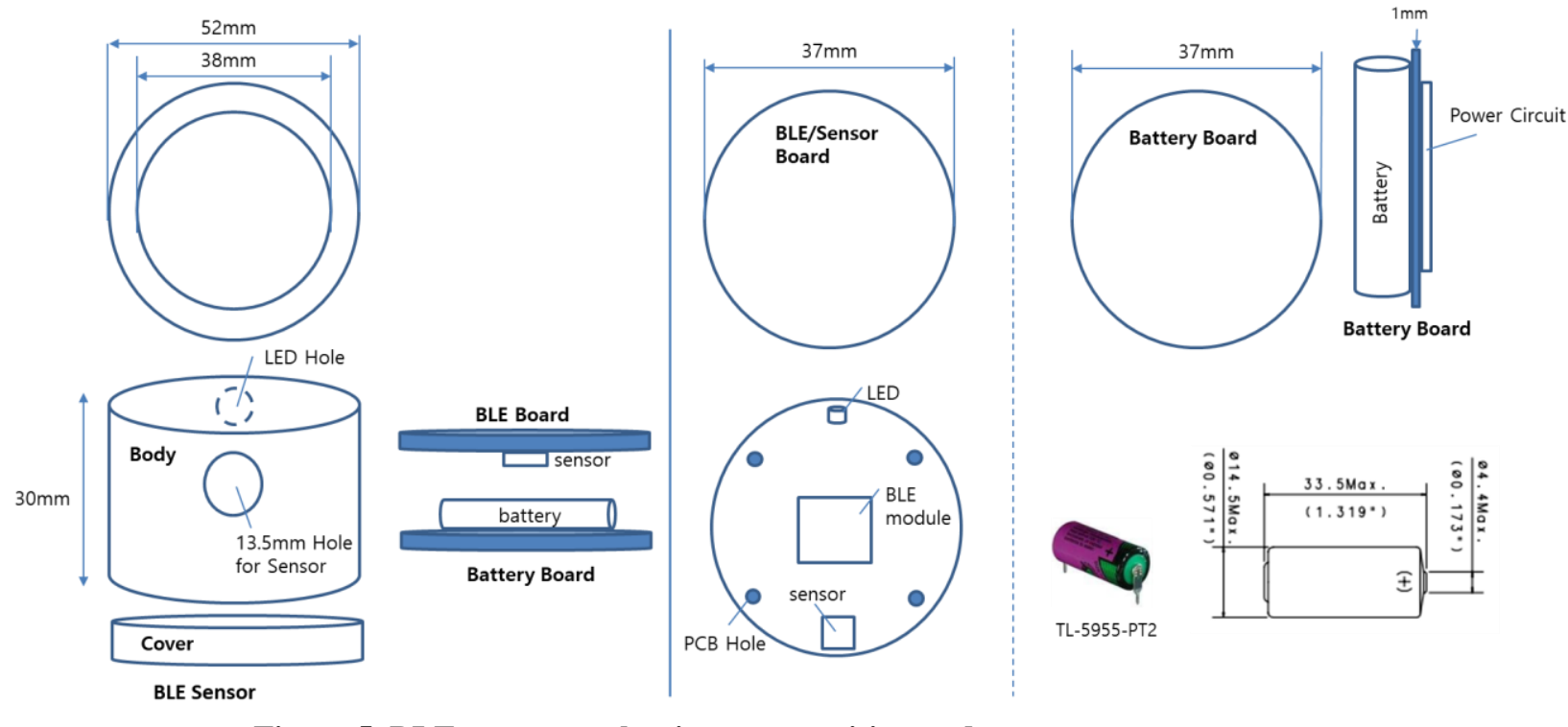

Figure 5. BLE sensor mechanism, composition and parts arrangement

Table 1: Sensor type/location/count/purpose according to monitoring equipment

\begin{tabular}{|c|c|c|c|c|}
\hline object & Sensor & $\begin{array}{c}\text { Installation } \\
\text { location }\end{array}$ & Count & Purpose of monitoring \\
\hline \multirow{4}{*}{ Battery rack } & Vibration sensor & Rack outer top & 1/Rack & Battery rack vibration abnormality detection \\
\hline & $\begin{array}{l}\text { temperature } \\
\text { Senser }\end{array}$ & Inside rack & 1/Rack & $\begin{array}{c}\text { Detect abnormal temperature inside the } \\
\text { battery rack }\end{array}$ \\
\hline & Offgas Sensor & Inside rack & 1/Rack & Offgas detection \\
\hline & Smoke sensor & Inside rack & 1/Rack & Smoke detection inside the battery rack \\
\hline \multirow{2}{*}{$\begin{array}{l}\text { Battery } \\
\text { room }\end{array}$} & $\begin{array}{l}\text { temperature } \\
\text { Senser }\end{array}$ & $\begin{array}{l}\text { Battery room } \\
\text { Entrance/Center }\end{array}$ & 2/Room & $\begin{array}{l}\text { Battery Room Condensation Diagnosis } \\
\text { Battery Room Air Conditioning Monitoring }\end{array}$ \\
\hline & Humidity sensor & $\begin{array}{c}\text { Battery room } \\
\text { Entrance/Center }\end{array}$ & 2/Room & $\begin{array}{l}\text { Battery Room Condensation Diagnosis } \\
\text { Battery Room Air Conditioning Monitoring }\end{array}$ \\
\hline
\end{tabular}

Table 2: Fire-level diagnosis, fire prevention/response according to action plan

\begin{tabular}{|c|c|c|c|c|}
\hline \multirow{2}{*}{ division } & \multicolumn{4}{|c|}{ fire } \\
\cline { 2 - 5 } & Step 1 & Step 2 & Step 3 & Step 4 \\
\hline Occurrence & Thermal Abuse & Off-gas generation & Smoke generation & Fire \\
\hline
\end{tabular}




\begin{tabular}{|c|c|c|c|c|}
\hline & Electrical Abuse & & & \\
\hline & Mechanical Abuse & & & \\
\hline $\begin{array}{l}\text { Diagnostic } \\
\text { method }\end{array}$ & $\begin{array}{c}\text { BMS } \\
\text { Temperature/humidity/ } \\
\text { Vibration sensor }\end{array}$ & Off-gas sensor & $\begin{array}{l}\text { Smoke detection } \\
\text { sensor }\end{array}$ & Flame sensor \\
\hline Measures & $\begin{array}{l}\text { Alarm occurrence } \\
\text { Manager Notice }\end{array}$ & $\begin{array}{l}\text { Local alarm alarm } \\
\text { Emergency stop } \\
\text { Electrical system } \\
\text { disconnection } \\
\text { Manager Notice }\end{array}$ & $\begin{array}{l}\text { Site alarm alarm } \\
\text { Emergency stop } \\
\text { System blocking } \\
\text { Firefighting started } \\
\text { Manager Notice }\end{array}$ & $\begin{array}{l}\text { Site alarm alarm } \\
\text { Emergency stop } \\
\text { System blocking } \\
\text { Firefighting } \\
\text { started } \\
\text { Manager Notice }\end{array}$ \\
\hline
\end{tabular}

\section{Conclusion}

This paper reported an edge safety-based on BLE 5.0 that is capable of detecting off-gas and detecting temperature, humidity, vibration, and smoke early in the golden time of approximately 10 minutes from the occurrence of thermal runaway inside the ESS to a fire. A system and ESS integrated safety management solution were proposed. In this study, internal monitoring of an ESS was possible by integrating directly with existing and new ESS. The administrator can observe all conditions on the web through the cloud-based ESS integrated safety management system. Nevertheless, more research will be needed to improve the ESS fire prevention system in the future.

\section{Acknowledgment}

This study is the result of research conducted by Jeollanam-do Province and Green Energy Research Institute as "Jeonnam Energy New Industry Commercialization Project (R\&D, R2-2019-04-01)".

\section{References}

1. Yichuan Niu, "Sizing and Coordinating Fast- and Slow Response Energy Storage Systems to Mitigate Hourly Wind Power Variation,” IEEE Trans. smart grid, Vol.9, 2

2. Jin-Tae Kim, "Analysis on AC Electrical Breakdown Characteristics of Insulation Barrier for Improvement of ESS", The transactions of The Korean Institute of Electrical Engineers 69(4), 2020.4, 581-585 (5 pages)

3. Il-Moo Lee, "A Study on the Safety Design Considerations for the fire Prevention of ESS", The transactions of The Korean Institute of Electrical Engineers 69(4), 2019.7, 1887-1888 (2 pages)Jenkins PF. Making sense of the chest x-ray: a hands-on guide. New York: Oxford University Press; 2005. p. 16. (Book)

4. Sang-Sun Yun, Seok-Cheol Kee, "Analysis of the Cell Balancing Effect on the ESS Fire by Simulating the Euljiro 3-ga Subway ESS”, THE TRANSACTIONS OF KOREAN INSTITUTE OF POWER ELECTRONICS 25(3), 2020.6, 219-226(8 pages)

5. Seoung-hee Lee, "Enhancement of the safety management system for 'Establishment and Revision of Electricity-related Laws': Passed the Electric Safety Management Act 22 years after the fire at the Busan refrigeration warehouse_Revised the enforcement regulations of the Electricity Business Act to prevent recurrence of ESS facility fires", Journal of Electrical World Monthly Magazine , 2020.5, 19-21(3 pages)

6. Jeong-In Lee, "A Study on the Identification Technique and Prevention of Combustion Diffusion through ESS (Energy Storage) Battery Fire Case”, Journal of the Korean Society of Disaster Information Vol. 16 No. 22020383-391 (9 pages)

7. Hoon Kim, Seung Ho Kim, Hyung-Jun Song, "DC Ground Fault Induced Fire Accident in Lithium Ion Battery based ESS", The transactions of The Korean Institute of Electrical Engineers 68(11), 2019.11, 1470-1476(7 pages)

8. Gi-Bum Nam, Soon-Hyung Lee, "ESS Fire Causes and Design Plans", The Korean Institute of Electrical Engineers, 2019.10, 39-41(3 pages)

9. Unhak Kim, Kiseok Shin, Seokwon Kang, "Study on Improvement of Dew Point within ESS Container for Fire Prevention", Journal of the Korean Society of Disaster Information Vol. 15, No. 22019165-174 (10 pages)

10. Suan Kim, Dongho Han, Jonghoon Kim, "Relative degradation grade Estimation based on Fuzzy logic 
algorithm for ESS battery fire protection", Power Electronics Conference, 2019.7, 441-442(2 pages)

11. Bisoy, S. K., Mallick, P. K., \& Mishra, A. Fairness Analysis of TCP Variants in Asymmetric Network. International Journal of Engineering \& Technology, 7(2.12), 231-233.

12. Pradhan, A., Bisoy, S. K., \& Mallick, P. K. (2020). Load balancing in cloud computing: Survey. In Innovation in Electrical Power Engineering, Communication, and Computing Technology (pp. 99-111). Springer, Singapore. 